
ФГАОУ ВО «Сибирский федеральный университет», e-mail: zea1@mail.ru

ПЕТРЕНКО ЕЛЕНА ВАЛЕРЬЕВНА старший преподаватель кафедры Товароведения и экспертизы товаров ФГАОУ ВО «Сибирский федеральный университет», e-mail: evp.2011@yandex.ru

\title{
DOI:10.26726/1812-7096-2020-07-95-101 \\ ЦИФРОВЫЕ ИНСТРУМЕНТЫ ОПОВЕЩЕНИЯ ОБ ОПАСНОЙ ПРОАУКЦИИ НА РЫНКАХ ЕАЭС И ЕС
}

\begin{abstract}
Аннотауия. Џель работы. В статье рассматривается отечественная и зарубежная практика использования цифровых ресурсов для оповещения об опасной продукции. Методы проведения работы. Проанализированы системы оповещения о опасной продукиии на рынках ЕАЭС и ЕС, выявлены их преимущеества и недостатки. Ресурс ФОедеральной службы по надзору в сфере защиты прав потребителей и благополучию человека недостаточно информативен, невозможно идентифицировать продукиию и типь нарущений. Cистема оповещения о опасных товарах Rapex более информативна. На информационном портале приводится подробная информащия о выявленных нарушениях: о наименовании, производителе и торговой марке, демонстрируется фотография товара, приводится характеристика типа риска, а также указываются предпринятые меры в отношении опасного товара. Данная информаиия является открытой, и с ней могут ознакомиться все участники рынка. Область применения результатов. Рассмотрена возможность использования опыта ЕС в отномении иифровых ресурсов для оповещения об опасной продукиии контрольно-надзорными органами и потребителями, предотвращения попадания ее на рынок. Выводы. ФОормирование единой информационной системы на рынках ЕАЭС о продукиии, не соответствующей требованиям технических регламентов, позволит субъектам рынка получать информацию не только об опасной продукции, но и мерах в отношении нее, принятых надзорными органами.
\end{abstract}

Ключевые слова: опасная продукция, система оповещения, информационный ресурс в области защиты прав потребителей, RAPEX.

ZAYCHENKO ELENA ANATOL YEVNA

Ph. D. in Economics, associate Professor of commodity Science and product expertise Federal STATE Autonomous educational institution "Siberian Federal University", e-mail: zea1@mail.ru

PETRENKO ELENA VALERYEVNA senior lecturer of the Department of commodity Science and goods expertise, Siberian Federal University, e-mail: evp.2011@yandex.ru

\section{DIGITAL HAZARD WARNING TOOLS PRODUCTS ON THE MARKETS OF THE EAEU AND EU}

Abstract. Purpose of work. The article discusses the domestic and foreign practice of using digital resources for warning about dangerous products. Methods of work. The article analyzes the warning systems for dangerous products on the markets of the EAEU and the EU, and identifies 
their advantages and disadvantages. The resource of the Federal service for supervision of consumer rights protection and human welfare is not informative enough, it is impossible to identify products and types of violations. The Rapex dangerous goods alert system is more informative. The information portal provides detailed information about the detected violations: the name, manufacturer and brand, shows a photo of the product, describes the type of risk, and indicates the measures taken in relation to the dangerous product. This information is open and available to all market participants. The scope of the results. The possibility of using the EU's experience with digital resources for warning about dangerous products by regulatory authorities and consumers and preventing them from entering the market is considered. Conclusions. The formation of a unified information system in the EAEU markets on products that do not meet the requirements of technical regulations will allow market participants to receive information not only about dangerous products, but also about measures taken by Supervisory authorities in relation to them.

Keywords: dangerous products, warning system, information resource in the field of consumer protection, $R A \rho E X$.

Введение. В настоящее время на территории Российской Федерации и Евразийского экономического союза реализуется ряд проектов в области цифровой экономики, направленных на создание цифрового пространства. В том числе, внедрение механизма мониторинга прослеживаемости товаров и цифровая маркировка отдельных видов товаров.

В рамках исполнения Стратегии государственной политики РФ в области защиты прав потребителей значительное внимание уделено созданию информационных ресурсов, помогающих потребителю сделать рациональный выбор товара. В том числе информируя его о характеристиках товара, случаях фальсификации и контрафакта, возможных рисках для здоровья и безопасности, маркировке $[1,8]$.

В мировой практике система информирования о безопасности и качестве товаров также является эффективным инструментом государственного контроля (надзора) за рынком.

В этой связи представляло интерес провести сравнительный анализ использования данных информационных ресурсов в странах ЕАЭС и ЕС надзорными органами и потребителями.

Методы исследования. На Федеральную службу по надзору в сфере защиты прав потребителей и благополучию человека в соответствии с Постановлением Правительства Российской Федерации от 16.02.2013 г. № 129 возложена обязанность по ведению государственного информационного ресурса в области защиты прав потребителей [2].

Основные цели формирования данного информационного ресурса:

- распространение достоверной информации по вопросам защиты прав потребителей, качества и безопасности товаров, в т. ч. в части соблюдения требований технических регламентов и электронной маркировки;

- предоставление доступа заинтересованным лицам (граждане, государственные органы, общественные организации) к информации о качестве и безопасности товаров.

Информационный ресурс представлен следующими разделами:

- модуль «Справочник потребителя»;

- модуль «Советы по здоровому питанию»;

- модуль «Нормативные правовые акты»;

- модуль «Информационно-аналитические материалы»;

- модуль «Органы и организации по защите прав потребителей»;

- модуль «Результаты проверок»;

- модуль «Продукция, не соответствующая обязательным требованиям»;

- модуль «Судебная практика»;

- модуль «Новости» [2].

Потребители могут ознакомиться с информацией об участии Роспотребнадзора в судебной защите прав потребителей (модуль «Судебная практика») с результатами проведенных проверок (модуль «Результаты проверок»). В соответствующих разделах содержатся информационно-аналитические материалы», сведения о продукции, не соответствующей обязательным требованиям. 
В модуле «Справочник потребителя» размещены образцы исковых заявлений, претензий в адрес хозяйствующих субъектов, памятки для потребителей, ответы на часто задаваемые вопросы в данной сфере и другая актуальная информация.

На наш взгляд, модуль «Продукция, не соответствующая обязательным требованиям» недостаточно информативен (рис. 1). Присутствуют только сведения о виде товара и группе нарушений. Не оглашается информация о производителе, торговой организации, в которой выявлена некачественная/опасная продукция, не детализируются виды опасности.

\begin{tabular}{|c|c|c|c|c|c|c|}
\hline \multirow[b]{2}{*}{$\mathrm{Ne}$} & \multirow{2}{*}{$\begin{array}{l}\text { Наименование продукции } \\
\text { Тип продукции }\end{array}$} & \multicolumn{3}{|c|}{ Прокзводитель } & \multirow{2}{*}{$\begin{array}{c}\text { Показатепи } \\
\text { несоответствия }\end{array}$} & \multirow[b]{2}{*}{ Perиoн } \\
\hline & & $\begin{array}{l}\text { Дата произ- } \\
\text { водства }\end{array}$ & Страна & $\begin{array}{l}\text { доку- } \\
\text { мент }\end{array}$ & & \\
\hline \multirow[t]{2}{*}{1} & $\begin{array}{l}\text { Футболка для девочки с } \\
\text { длинным рукавом, Cegisa цвет } \\
\text { синий }\end{array}$ & & & & \multirow{2}{*}{$\begin{array}{l}\text { Маркировка не } \\
\text { соответствует, } \\
\text { Подтверждающие } \\
\text { документы отсутствуют }\end{array}$} & \multirow[t]{2}{*}{ Камчатский край } \\
\hline & $\begin{array}{l}\text { Продукция предназначенная } \\
\text { для детей и подростков }\end{array}$ & & & & & \\
\hline \multirow{2}{*}{2} & $\begin{array}{l}\text { Водолазка для девочки, цвет } \\
\text { сини }\end{array}$ & & & & \multirow{2}{*}{$\begin{array}{l}\text { Маркировка не } \\
\text { соответствует, } \\
\text { Подтверждающие } \\
\text { документы отсутствуют }\end{array}$} & \multirow{2}{*}{ Камчатский край } \\
\hline & $\begin{array}{l}\text { Продукция предназначенная } \\
\text { для детей и подростков }\end{array}$ & & & & & \\
\hline \multirow[t]{2}{*}{3} & $\begin{array}{l}\text { Футбопка дпя девочки с } \\
\text { длинным рукавом,Benini цвет } \\
\text { синий }\end{array}$ & & & & \multirow{2}{*}{$\begin{array}{l}\text { Маркировка не } \\
\text { соответствует, } \\
\text { Подтверждающие } \\
\text { документы отсутствуют }\end{array}$} & \multirow[t]{2}{*}{ Камчатский край } \\
\hline & $\begin{array}{l}\text { Продукция предназначенная } \\
\text { для детей и подростков }\end{array}$ & & & & & \\
\hline
\end{tabular}

Pис.1. Продукичя, не соответствующая обязательным требованиям

Для сравнения, независимые организации, задействованные в процедуре мониторинга потребительского рынка (Росконтроль, Российская система качества), имеют достаточно информативные электронные ресурсы, на которых потребитель может ознакомиться с информацией о результатах проведенных исследований и рейтинговой оценке, черном списке опасной продукции, рекомендациях по выбору товара [3,4].

В Красноярске такой ресурс представлен в лице проекта «Проднадзор», который курирует ФБУ «Красноярский ЦСМ». В рамках рейтинговой оценки метод потребительского тестирования был апробирован на примере таких групп товаров, как мультиварки, женские колготки, детская одежда, кожгалантерейные изделия, новогодние ели, санки, коньки фигурные и для игры в хоккей.

В этой связи целесообразно использовать опыт Европейского союза, где на межгосударственном уровне внедрена система оперативного оповещения о некачественных и опасных непродовольственных товарах (RAPEX) [6].

Система быстрого обмена информацией RAPEX функционирует на рынке Европейского союза с 2003 г. и охватывает 31 страну.

Основная цель RAPEX - предотвращение или ограничение продажи и использования непродовольственных товаров, представляющих серьезную угрозу для здоровья и безопасности потребителей.

Система RAPEX позволяет:

- осуществлять оперативный обмен информацией между государствами-членами ЕС о меpax, принятых для предотвращения и ограничения сбыта или использования продукции, представляющей собой серьезную опасность для здоровья и безопасности потребителей;

- контролировать торговые отношения ЕС как внутри союза, так и с третьими странами и собирать информацию о недобросовестных поставщиках;

- контролировать исполнение мер по отношению к опасным товарам, предписанных национальными органами управления, и отслеживать меры, принимаемые производителями и дистрибьюторами на добровольной основе [12]. 


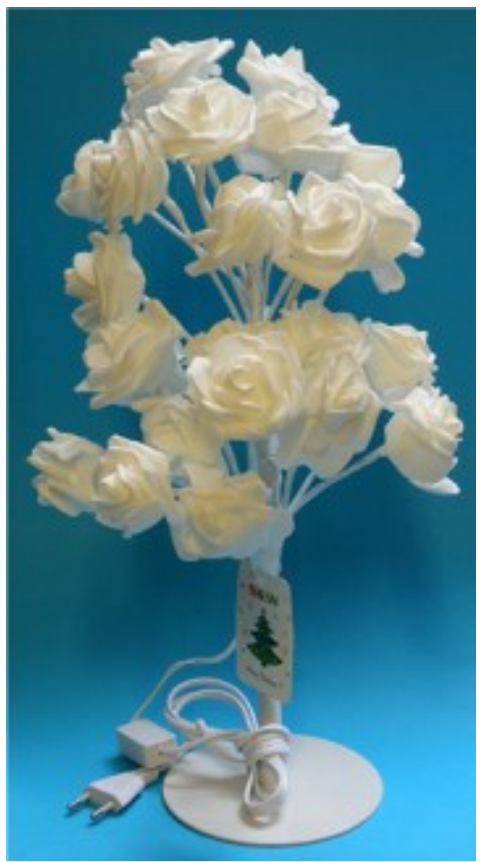

Номер оповещения: A12/00590/20

Продукт: Сеть освещцения

Название: Рокдественская елка / mū karácsonyfa

Штрих-код: 8588586629278

Номер партии: Неизвесто

Tип оповещения: Серьезный

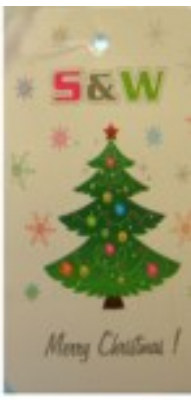

ITEM NO:62927

(40): miksistants

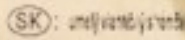

(HR): Ancot:strestat

(RO): Pomde Craciun

(CN): Christastre 8 588588629278

SZARM:P.R.C

EGEZSEGRE KAROSANYAGOT

NEMTARTALMAZ O I

Tип риска: ожоги, поражение электрическим током, покар

Кабели ме закрепnены надлежацим образом, слишком тонкие и ме имект надлежащей изопяции. Кроме того, размеры и изолация сетевой вилки не подходят. Следовательно, пользователь может коснуться доступных частей под напрякеншем и попучить удар током Кроме того, кабели могут перегреваться при нормальном использовании, что может вызвать ожоги пользователя или даже привести к пожару. / Продукт не соответствует требованиям Директивы по низковопьтному оборудованию и европейского стандарта EN 60598 .

Меры, предписанмые государственными органами (дистрибыютору): отзыв продукта у конечных попьзователей, отзыв продукта с рынка

Описание: Декоративная лампа в форме дерева с 24 белыми светодиодами. Светодиоды имеют белые розовые абакуры.

Описание упаковки: Упаковка: прозрачный пластиковый пакет

Страна происхождения: Китайская Народная Респубпика

Уведомление отправлено: Венгрия

Puc. 2. Структура отчета RAPEX об опасной продукиии

С публикацией еженедельных отчетов о товарах с нарушениями (рис. 2), с указанием следующей информации об объекте:

- номер оповещения;

- категория; фото и описание образца товара;

- наименование изделия;

- торговая марка;

- тип/номер модели;

- номер партии/штрих-код;

- страна происхождения;

- тип риска (описание риска, номер европейского стандарта);

- меры, принятые экономическими операторами;

- меры, предписанные государственными органами (например, импорт отклонен на границе, отзыв продукта у конечных пользователей, вывод продукта с рынка).

Эффективность системы оценивается посредством статистического анализа уведомлений о 
небезопасных продуктах в системе быстрого оповещения, структуре выявленных рисков, ответных мер реагирования со стороны надзорных органов. Анализ размещенных сведений позволяет провести корреляцию между применяемой процедурой оценки соответствия и несоответствующей продукцией, проанализировать ситуацию на рынках конкретных стран в разрезе товарных групп и видов нарушений, скорректировать перечень контрольно-надзорных мероприятий $[9,10,11,14]$.

Например, в 2018 г. через RAPEX было распространено 2257 оповещений о потенциально вредных товарах. Наибольшее количество рисков, связанных с безопасностью, было выявлено по следующим товарам: игрушки (31\%), транспортные средства (19\%), одежда и текстиль $(10 \%)$, электробытовые товары (8\%) и косметика $(7 \%)$.

Среди наиболее часто встречающихся потенциальных рисков - воздействие вредных химических веществ, травмы и ранения (25\%), случайное удушение $(19 \%)$, электрический шок $(10 \%)$, пожарная опасность (8\%).

На национальном уровне наибольшее количество выбывших продуктов зафиксировано в Германии (362), Франции (249) и Польше (139). Наибольшее количество потенциально опасной продукции поступает из Китая (64\% запретов). На европейскую продукцию приходится в среднем до $14 \%$, на Турцию - $3 \%$ и у $7 \%$ товаров, попавших под запрет, не указана страна происхождения $[14,16]$.

C 2010 г. в RAPEX отслеживаются риски и для окружающей среды (угроза загрязнения водоемов, воздуха, почвы, негативное влияние на флору и фауну).

Надзорные органы государств ЕС обязаны проверить национальные рынки на предмет наличия на них потенциально опасных товаров из оповещения и при необходимости принять меры по выводу их с рынка.

Следует отметить, что база данных европейской системы оповещения открыта не только для надзорных органов, но и для всех пользователей интернета.

Увеличение объемов продаж на интернет-порталах потребовало разработки дополнительных инструментов мониторинга онлайн- предложений. Были созданы группы веб-скрининга для выявления опасных товаров. В 2018 г. 16\% предупреждений, отправленных на портал RAPEX, были связаны с онлайн-продажами [13].

В этой связи Европейская комиссия подписала соглашение с ведущими онлайнплатформами (Amazon, Alibaba, Ebay и RakutenFrance) по отзыву опасных потребительских товаров с продажи в течение от двух до пяти рабочих дней со дня получения уведомления от национальных органов стран ЕС.

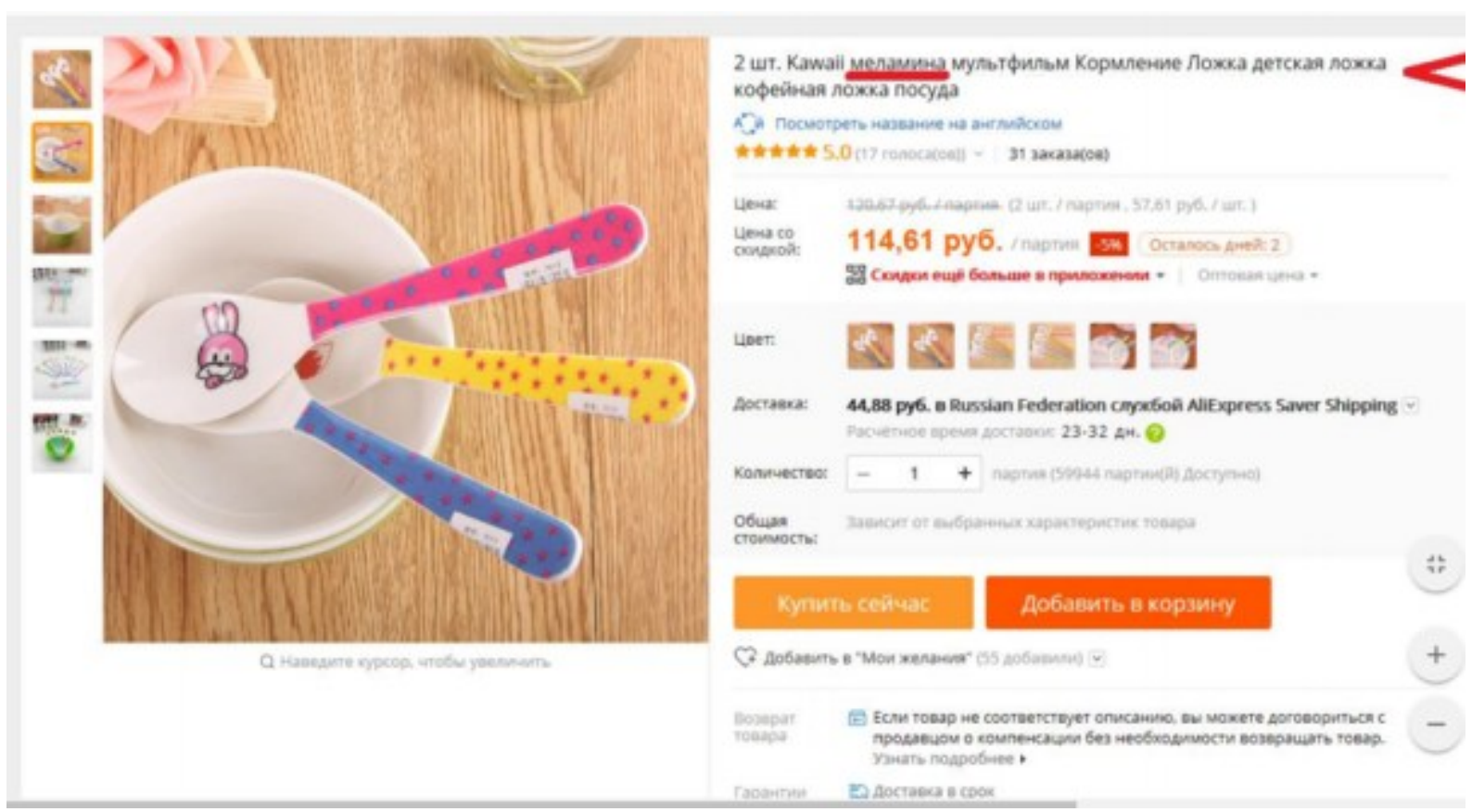

Puc. 3. Описание товара с сайта AliExpress 
В России подобное исследование было проведено в 2017 г. на примере детской продукции (одежда, игрушки, посуда), реализуемой на торговой площадке AliExpress (рис. 3).

Например, были выявлены следующие нарушения:

- ложки для кормления из меламина (запрещено п.3 ст.4 ТР ТС 007/2011 О безопасности продукции, предназначенной для детей и подростков);

- погремушки с поверхностной росписью (запрещено п.3.2 ст.4 ТР ТС 008/2011 О безопасности игрушек).

Но каких-либо кардинальных мер в отношении отзыва опасной продукции предпринято не было.

Результаты. В Евразийском экономическом союзе подобный формат реализуется в виде пилотного проекта по формированию системы информирования о продукции, не соответствующей требованиям технических регламентов ЕАЭС $[6,15,17]$.

На первом этапе выявлялись случаи несоответствия по таким группам товаров, как молочная и мясная продукция, игрушки, продукция для детей и подростков. Низковольтное оборудование и колесные транспортные средства.

В дальнейшем планируется распространить действие проекта и на другие технические регламенты ЕАЭС.

По результатам проекта будет создан межведомственный информационный ресурс о выявленных случаях обращения на рынке опасной продукции $[19,20]$.

Перечень информации, размещаемой на информационном ресурсе, будет включать в себя сведения о:

- мероприятиях и результатах государственного надзора;

- мерах по устранению негативных последствий выявленных нарушений;

- случаях продажи товаров без документов подтверждения соответствия (сертификат/ декларация о соответствии).

В отношении товаров, не соответствующих требованиям безопасности технических регламентов ЕАЭС и выявленных на территории союзного государства, возможно их изъятие из обращения на всей территории ЕАЭС,

К сожалению, сроки пилотного проекта были сдвинуты до июня 2020 г. Из 14 уполномоченных органов контроля (надзора) информацию по проекту предоставили только шесть - из Армении, Беларуси и Кыргызстана. Российские и казахстанские органы участия в тестовой эксплуатации не принимали. Это не позволило своевременно завершить реализацию пилотного проекта и выполнить поставленные задачи в полном объеме.

Выводы. Если данный проект будет реализован, единая информационная система позволит субъектам рынка получать информацию не только об опасной продукции, но и мерах в отношении нее, принятых надзорными органами.

Литература

1. Стратегия государственной наииональной политики РФ на период до 2025 г. Указ Президента РФ om 19.12.2012 2. $N 1666$.

2. Федеральная служба по надзору в сфере защиты прав потребителей и благополучия человека. - URL : http://rospotrebnadzor.ru.

3. Офиииальный сайт Росконтроль. - URL : https://roscontrol.com/.

4. Офиџиальный сайт национальной системы мониторинга качества Роскачество. - URL : https:// rskrf.rul.

5. Сайт Евразийского экономического союза. - URL : http://www.eaeunion.org/.

6. Сайт Европейской комиссии. - URL : http://www.eurasiancommission.org/ru/nae/news/Pages/04-12-2019-

1.aspx.

7. Quality and safety of consumer goods : digital transformation of information resources / E.A. Zaychenko, E.V.

Petrenko, V.V. Polyanskaya, V.N. Parshikova // IOP Conference Series : Earth and Environmental Science.

V. 421 (3).

8. Защита прав потребителей в Российской Федераиии в 2018 г.: государственный доклад. - М. : Федеральная служба по надзору в сфере защиты прав потребителей и благополучия человека, 2019.

9. Safety Gate : just a click to keep away from dangerous products 2018 results of the Rapid Alert System for dangerous non-food products. - Moscow : European Union, 2019.

10. Safety Gate : Rapid Alert System for dangerous non-food products - most recent alerts. - URL : https:// ec.europa.eu/consumers/consumers_safety/safety_products/rapex/alerts/?

event=main.immediatlyPublishedNotifications\#main-nav.

11. Product Safety Business Alert Gateway User manual for producers and distributors . - URL : https:// 
ec.europa.eu/consumers/consumers_safety/safety_products/rapex/alerts/repository/content/pages/rapex/docs/ User\%20Manual.pdf.

12. Директива 2001/95 / ЕС Европейского Парламента и Совета от 3 декабря 2001 г. об общей безопасности продукции. - URL : https://eur-lex.europa.eu/legal-content/EN/ALL/? uri=CELEX:32001L0095.

13. Commission notice On the market surveillance of products sold online // Official Journal of the European Union, $2017.2-\quad$ URL : $\quad$ https://eur-lex.europa.eu/legal-content/EN/TXT/? uri=uriserv:OJ.C .2017.250.01.0001.01.ENG

14. Vincze, S., Al Dahouk, S, Dieckmann, R Microbiological safety of non-food products : What can we learn from the RAPEX database? // International Journal of Environmental Research and Public Health, 2019.

15. Информационно-аналитический отчет : анализ мирового опыта развития промышленности и подходов к ичифровой трансформации отраслей экономики государств-членов Евразийского экономического союза. - М. : Департамент промышленной политики, 2017.

16. Michalek, I. M., Liu, B., Benn, E. K., Santos, Gaetano dos F. L. Skin lightning products' violations in Europe : An analysis of the rapid alert system for dangerous non-food products 2005-2018 // Regulatory Toxicology and Pharmacology. 2019. C. 50-54.

17. Доклад о развитии ицирровой (интернет) торговли ЕАЭС. - М. : Евразийская экономическая комиссия, 2019.

18. Контрольно-надзорная и разрешительная деятельность в Российской Федерации : аналитический доклад. - М., 2018.

19. Пилотный проект по формированию системы информирования о продукции, не соответствующей требованиям ТР ЕАЭС. Решение Коллегии ЕЭК от 10 мая 2018 г. № 74.

20. Временный порядок взаимодействия уполномоченных органов государств-членов Евразийского экономического союза и Евразийской экономической комиссии при реализачии пилотного проекта по формированию системы информирования о продукции, не соответствующей требованиям технических регламентов Евразийского экономического союза. Решение Коллегии ЕЭК от 12 ноября 2018 г. №182.

\section{References:}

1. Strategiya gosudarstvennoj nacional'noj politiki RF na period do $2025 \mathrm{~g}$. Ukaz Prezidenta RF ot 19.12.2012 g. $N 1666$.

2. Federal'naya sluzhba po nadzoru $v$ sfere zashchity prav potrebitelej i blagopoluchiya cheloveka. - URL : http://rospotrebnadzor.ru.

3. Oficial'nyj sajt Roskontrol'. - URL : https://roscontrol.com/.

4. Oficial'nyj sajt nacional'noj sistemy monitoringa kachestva Roskachestvo. - URL : https://rskrf.ru/.

5. Sajt Evrazijskogo ekonomicheskogo soyuza. -URL : http://www.eaeunion.org/.

6. Sajt Evropejskoj komissii. - URL : http://www.eurasiancommission.org/ru/nae/news/Pages/04-12-2019-1.aspx.

7. Quality and safety of consumer goods : digital transformation of information resources / E.A. Zaychenko, E.V. Petrenko, V.V. Polyanskaya, V.N. Parshikova // IOP Conference Series : Earth and Environmental Science. V. 421 (3).

8. Zashchita prav potrebitelej v Rossijskoj Federacii v 2018 g.: gosudarstvennyj doklad. - M. : Federal'naya sluzhba po nadzoru $v$ sfere zashchity prav potrebitelej i blagopoluchiya cheloveka, 2019.

9. Safety Gate : just a click to keep away from dangerous products 2018 results of the Rapid Alert System for dangerous non-food products. - Moscow : European Union, 2019.

10. Safety Gate : Rapid Alert System for dangerous non-food products - most recent alerts. - URL : https:// ec.europa.eu/consumers/consumers safety/safety products/rapex/alerts/?

event=main.immediatlyPublishedNotifications \#main-nav.

11. Product Safety Business Alert Gateway User manual for producers and distributors . - URL : https:// ec.europa.eu/consumers/consumers_safety/safety_products/rapex/alerts/repository/content/pages/rapex/docs/ User\%20Manual.pdf.

12. Direktiva 2001/95 / EC Evropejskogo Parlamenta i Soveta ot 3 dekabrya 2001 g. ob obshchej bezopasnosti produkcii. - URL : https://eur-lex.europa.eu/legal-content/EN/ALL/?uri=CELEX:32001L0095.

13. Commission notice On the market surveillance of products sold online // Official Journal of the European Union, 2017. - URL : https://eur-lex.europa.eu/legal-content/EN/TXT/?

uri=uriserv:OJ.C .2017.250.01.0001.01.ENG.

14. Vincze, S., Al Dahouk, S, Dieckmann, R Microbiological safety of non-food products : What can we learn from the RAPEX database? // International Journal of Environmental Research and Public Health, 2019.

15. Informacionno-analiticheskij otchet : analiz mirovogo opyta razvitiya promyshlennosti i podhodov $k$ cifrovoj transformacii otraslej ekonomiki gosudarstv-chlenov Evrazijskogo ekonomicheskogo soyuza. - M. : Departament promyshlennoj politiki, 2017.

16. Michalek, I. M., Liu, B., Benn, E. K., Santos, Gaetano dos F. L. Skin lightning products'violations in Europe: An analysis of the rapid alert system for dangerous non-food products 2005-2018// Regulatory Toxicology and Pharmacology. 2019. S. 50-54.

17. Doklad o razvitii cifrovoj (internet) torgovli EAES. - M. : Evrazijskaya ekonomicheskaya komissiya, 2019.

18. Kontrol'no-nadzornaya i razreshitel'naya deyatel'nost'v Rossijskoj Federacii : analiticheskij doklad. - M., 2018.

19. Pilotnyj proekt po formirovaniyu sistemy informirovaniya o produkcii, ne sootvetstvuyushchej trebovaniyam TR EAES. Reshenie Kollegii EEK ot 10 maya 2018 g. № 74.

20. Vremennyj poryadok vzaimodejstviya upolnomochennyh organov gosudarstv-chlenov Evrazijskogo ekonomicheskogo soyuza i Evrazijskoj ekonomicheskoj komissii pri realizacii pilotnogo proekta po formirovaniyu sistemy informirovaniya o produkcii, ne sootvetstvuyushchej trebovaniyam tekhnicheskih reglamentov Evrazijskogo ekonomicheskogo soyuza. Reshenie Kollegii EEK ot 12 noyabrya 2018 g. №182. 